\title{
'Choice': what we mean by it, and what that means for preventing childhood obesity
}

\author{
Christine M Porter ${ }^{1,2, *}$ \\ 'Division of Kinesiology \& Health, University of Wyoming, Room 117, Corbett Building, Dept 3196, 1000 E. \\ University Ave., Laramie, WY 82071, USA: ${ }^{2}$ Division of Nutritional Sciences, Cornell University, Ithaca, \\ NY, USA
}

Submitted 24 August 2011: Accepted 26 January 2012: First published online 6 March 2012

\begin{abstract}
Objective: (i) To map how US adults value 'choice' in the context of obesity policy and (ii) to discuss implications for obesity prevention in children.

Design: Semi-structured interviews ( $n$ 105) were conducted between 2006 and 2009 about causes of and solutions to childhood obesity. Quotes captured in field notes from community meetings ( $n 6$ ) on childhood obesity prevention were also analysed. Each use of the word 'choice' and its variants was identified in these texts. Content and discourse were analysed to identify the implied values and meaning in each use.

Setting: North-eastern USA.

Subjects: One hundred and five adults, some involved in childhood obesity prevention initiatives.

Results: Three distinct frames of 'choice' emerged: (i) having choices (choice as freedom), (ii) making choices (choice as responsibility) and (iii) influencing choices (contextual constraints and impacts on choice). Many speakers used more than one frame over the course of an interview. Most people using the third frame seemed to share the values behind the first two frames, but focused on conditions required to enable people to be accountable for their choices and to make truly free choices. A small subset thought outside the frame of individual choice, valuing, as one person put it, a 'social contract'.

Conclusions: Public debate in the USA about responsibility for and solutions to rising obesity rates often hinges on notions of 'choice'. These frames, and the values underlying them, are not mutually exclusive. Respecting the values behind each 'choice' frame when crafting obesity prevention policy and employing all three in public communications about such policy may facilitate greater consensus on prevention measures.
\end{abstract}

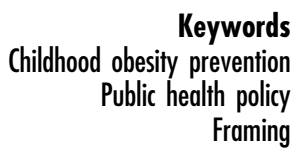

The USA has become (in)famous for the fatness of its people. The federal government has begun concerted efforts to tackle childhood obesity, as signalled by the White House's 'Let's Move' initiative. However, in a country perhaps equally famous for valuing individualism and personal freedom, obesity prevention policy proposals often face opposition, particularly from the political right, as interfering with 'choice'.

The current paper examines ways adults living in the north-east of the USA talked about and valued 'choice' in relation to obesity prevention during interviews ( $n$ 105) and in the course of community meetings about childhood obesity ( $n$ 6). It then discusses implications for developing policy and public health messages for obesity prevention in the USA, particularly among children.

\section{Methods}

\section{Data}

The paper draws from three sets of semi-structured interviews with adults about childhood obesity prevention (105 in total), particularly the roles of communities in prevention.

1. Set A interviews ( $n$ 29) were conducted in 2006 with stakeholders in child health and well-being in an upstate New York community as part of founding a new community childhood obesity prevention initiative. Participants were asked for their views on the causes of and solutions to childhood obesity. They were recruited through strategic snowballing, with the 'strategic' part being recalibration of recruitment to 
achieve demographic diversity and to include key stakeholders in community childhood obesity prevention (e.g. parents, teachers, medical professionals, human service professionals). Set A interviews were conducted by a graduate student research team and transcribed. Quotes from these interviews reproduced herein are identified with '(a)'.

2. Set B interviews ( $n$ 54) were conducted in 2009 following a research exercise that asked a different set of people in that same community to sort statements about the role communities should play in childhood obesity by how much they agreed or disagreed with each $^{(1)}$. Participants were also recruited through strategic snowballing. Interviewers asked participants why they sorted the way that they did. Set B interviews were conducted by a team of undergraduate and graduate students and transcribed. Quotes from these are identified with '(b)'.

3. The author conducted set $C$ interviews ( $n$ 22) in 2009 and 2010. Participants were members of one of three community-based childhood obesity prevention projects being studied in the north-eastern USA. These interviews were in depth and open ended about community strategies for preventing childhood obesity. In addition to the interviews, detailed notes were taken at community meetings ( $n$ 6) of these projects. Participant comments recorded in these field notes were also included in analysis. Quotes from these sources are identified with '(c)'.

None of these interviews or meetings was explicitly about 'choice' vis-à-vis obesity prevention. Cornell University's Institutional Review Board approved the studies involved in this research and interested individuals consented to participate.

Unless otherwise noted, all quotations used here are from these interviews or meetings. Individuals quoted are identified by a combination of a letter, which indicates their interview set ( $a, b$ or $c$ ), and a number, which identifies individual interviewees within each set.

\section{Analysis}

Using the qualitative data analysis software ATLAS.ti version 5.6.3 (ATLAS.ti GmbH, Berlin, Germany), interview transcripts and notes were coded for uses of the word 'choice' and its variants (e.g. chose, choices, choose) and for synonyms when their use related to decision making (e.g. decide, options, decision). In the reports generated of these coded passages, each use of these terms was analysed for its framing.

Frames are the 'metamessages' in which we embed our communications, consciously or otherwise, largely determining their meaning ${ }^{(2,3)}$. Framing heavily influences interpretation and understanding, including indicating how we should understand an issue; 'framing is about more than a message. It is about what a society values ${ }^{,(4)}$. In most cases the framing was transparent, as in most of the quotes presented here. In the few cases it was not, grammatical critical discourse analysis tools were used to pick apart the sentences (e.g. whether actors were individuals or institutions; if verbs expressed an obligation or command) ${ }^{(5,6)}$.

\section{Results: three kinds of 'choice'}

Talk in these interviews and meetings about obesity prevention framed 'choice' in three ways: (i) choice as freedom, (ii) choice as responsibility or (iii) choice as impacted by context. Some people blended these frames, but nearly every instance of 'choice' talk fit one or more of these three. Examples are given below.

\section{Having choices (freedom, autonomy)}

One frame cast choice as freedom to choose from a variety of options, especially food options, with minimal restrictions. For example, a school food director described the crux of the job as providing a variety of food choices to students, including the majority who 'don't have a problem' with weight (c1). One person said, 'I think people have a sense of empowerment when they can choose' (b1). This choice-as-freedom frame assumes and values individual autonomy. For example, one parent and youth worker expressed mixed feelings about pressuring restaurants to offer healthier child menus, 'I'm a big protector of individual freedom and personal choice... The opposite end of the spectrum has this big brother, "I'll tell you what to eat, this is how to live" kind of thing' (b2).

Some noted a need for information to help navigate these choices; for example, 'freedom has to do with making choices and to make choices you need the information about the choices that you're making' (b21) and 'let people have choices, let them make educated choices' (b3). This expressed need for education or information bleeds into the 'context' for choice frame, below.

\section{Making choices (responsibility, accountability)}

A second framing was choice as individual responsibility. A parent at a Women, Infants, and Children (WIC) clinic used this frame when she said:

I shouldn't be going to a fast-food restaurant in the first place but if I happened to go, then there's a choice, either getting something crispy or grilled. That's really on me. I think it falls on ourselves to make the right choice. (a1)

The words 'shouldn't' and 'right' are value-laden. So is the word 'accountable', as in 'if they had fresh produce at the food pantry then they would have that choice, then they could be more accountable to choose fresh produce over the junk food' (b4). This latter quote also bleeds into the context frame, with conditions of availability being 
necessary to render someone accountable for their choice in this case. Several of the participant comments in the next section on the 'context' frame also use a responsibility frame.

\section{Influencing choices (context)}

A third framing widened the picture to include policy and other environmental contexts for individual choice. The oft-repeated health promotion goal of 'making the healthy choice the easy choice' epitomizes this frame.

In these data, those who employed a context-for-choice frame usually accepted the moral values underlying the individual frames while challenging their assumptions. For example, people occasionally used this frame to highlight private-sector $v$. state threats to freedom. One person said, 'putting all the power in all the [food] production and in the distribution, rather than in the consumer, although it's voiced as giving it to the consumer, this is an esoteric trick' (b5). Another argued, 'making people fat protects capitalism but it doesn't protect individual freedom' (b1).

Most often, while accepting or even advocating the individual responsibility ethic, the context frame was employed to question 'response-ability ${ }^{\text {(7) }}$ assumptions, asking how able people are to make healthy choices. For example:

You can't tell people what to buy in the supermarket for their home use. But hopefully if there's enough education out there then they would make some healthy choices. (a2)

How do you expect families that are struggling to be healthier if they can't afford it? (b6)

I don't agree that parents actually have the ability to take responsibility. Yes, they should take responsibility, but for various reasons it can be hard. (b7)

These examples employ the responsibility frame, but make that individual accountability contingent on improving contexts for choice.

However, this context frame does not inherently encompass the values underlying the two individual frames. For example, reacting to a statement explicitly in a choice-as-freedom frame, one person argued, 'what that perspective calls a nanny state the rest of us call a functioning society, abiding by a social contract' (b8). This assigns value to the group, not just the individual.

\section{Discussion}

In the course of a conversation, many participants talked about choice in two or even all three ways. Although the values underlying the three choice frames were not always shared among these interview participants, they are not mutually exclusive.

The freedom frame encompasses the strong value of individual autonomy in the USA. Public debates about obesity prevention policy often use this choice frame. In an extreme version, the political right in the USA often invokes fears of a 'nanny state' in opposition to regulation, including obesity prevention policies, in the name of defending individual autonomy. See, for example, a book of that title lamenting 'food fascists' ${ }^{\text {(8) }}$. But the use of this frame spans the political spectrum. For example, when San Francisco's mayor vetoed legislation that would have banned toys in children's fast-food meals, he argued, 'parents, not politicians, should decide what their children eat, especially when it comes to spending their own money. Despite its good intentions, I cannot support this unwise and unprecedented governmental intrusion into parental responsibilities and private choices,(9). Similarly, the Washington DC Council Chair noted in a public roundtable that 'it's wrong that the schools don't give [schoolchildren] a choice to have chocolate milk anymore $^{,(10)}$.

The moral responsibility frame reflects conventional American values of self-control and willpower and, perhaps, a direct health imperative ${ }^{(11)}$. Americans tend to make moral judgements of others by the healthfulness of what they eat ${ }^{(12)}$ and view obese people as morally lacking $^{(13)}$. This frame tends to accept the freedom frame and assume individual autonomy.

Values underlying the context-for-choice frame varied, as mentioned in the results. However, with few exceptions, the discourses about choice tended to endorse or, at least, assume core values of freedom and of personal responsibility. The differences usually lay not in these underlying values, but in beliefs about how much power people have to choose. For example, the two people quoted below differ on what counts as enabling autonomous choice:

God gave us all free choice. Once you get the knowledge that changes your free choice. Once you know this is how to eat to maintain a healthy lifestyle and then you choose not to do it, then it's on you. Instead of making it a law, you give people the knowledge. (b16)

While some people can have this personal choice, most of the people who are obese, overweight or unhealthy because of food they eat don't necessarily have the choice. I don't believe that even with the knowledge and education everyone has the equal ability to change and make the choice. (b17)

One suggests knowledge suffices while the other believes it takes more. Often, the positions expressed on what supports are adequate to confer autonomy (and, with that, responsibility) were 'soft', with many people using more than one frame. For example, the person quoted first above also said 'it's not fair to expect struggling families to have the energy and determination it takes to eat well' and that you 'can't really blame' parents who keep children inside for safety (b16). Similarly, the 
WIC participant who noted her responsibility for choosing grilled over crispy food later mentioned she'd like to eat healthier and organic, 'but it's not in my reach. Not by a long shot' (a1). Another parent picking up WIC cheques was explicit about both the capacity and context for her food choices: 'I think if you're determined to have a healthy diet that you find ways to work with it but I know that when I go in the grocery store all the junk food is cheaper' (a2). A community organizer argued, 'stop blaming people for bad choices, help start naming obstacles' (c4).

As a more extreme version of enabling healthy choices, some used the context frame exclusively, focusing on the structure side of the classic structure $v$. agency dialectic. As one public health professional said, 'I tend not to think of things in terms of choice because my background is systems... as opposed to promoting choices, just creating a structure that's naturally healthy' (c2). Another health professional took this even further, proposing merit in approaches that 'make the healthy choice the only choice' (c3).

The current research was not designed to map the prevalence of each frame. However, previous research on cause and responsibility frames as portrayed in the media and expressed in opinion surveys indicates that the 'context' frame likely places a distant second to the responsibility frame in the USA. In one survey, 91\% agreed that parents bear 'a lot of responsibility' to reduce childhood obesity ${ }^{(14)}$. Television advertising placed a distant second at $45 \%$ and government was last, at $17 \%$. Analysis of popular media coverage of childhood obesity has found a rise in attribution of causes of the problem to systemic or environmental factors ${ }^{(15,16)}$ - congruent with the context frame - but this does not appear to have translated into social responsibility (as opposed to individual responsibility) frames for solutions ${ }^{(16,17)}$.

However, it bears repeating that these frames are complex and not mutually exclusive. Also, the freedom frame for choice does not map to this previous research, although it is possible that the low ranking of government responsibility might stem from this frame as much as from causal beliefs. Also, the genetics/biology causal frames found in previous media analyses did not surface in these participants' discussions of choice. Perhaps this theme resonates more in academia, and media reports on research, than in the public at large. Potential reasons might be complexity and inconclusiveness of such research, clash with the dominant responsibility frame, and/or practical irrelevance given that genetic factors are immutable. These bear exploration in future research.

\section{Cbildren and choice}

Like in the veto argument that San Francisco's then-mayor made about toys in fast-food meals, many participants talked about parental freedom and parental responsibility in lieu of the child's.
A number of people proposed restricting choices for children as a palatable way to enforce healthier choices under the assumption that children may not yet have the capacity to choose wisely. For example, a family services provider said, 'children don't have the same reasoning as adults... even if they're a kid that eats healthy at home, a lot of kids, if they see two choices and they see junk food versus healthy food, they're going to go for the junk food, unfortunately' (b4). A parent said, 'decisions on what to eat are personal choices, but the schools should focus on providing just healthy foods' (b11). Another echoed this sentiment with, 'I think the decision about what types of food to eat is a personal choice. If you don't like what is at the school or youth center, you could supplement it somewhere else, but I think schools and youth centers have a responsibility to promote the health of the people' (b12). A third took this argument further:

If parents do teach their kids well, but schools have vending machines with unhealthy food and drinks for profits, schools override parents' right to make choices for their children. They are taking away a parent's right to teach and enforce their kids' healthy habits. (b13)

Employing this transfer of accountability in the 'making choices' frame, one person said, 'when you see a 6-yearold and they're like damn near 100 pounds the first thing that runs through your mind is "what the hell are their parents doing?", (b14). A former teacher argued, 'I saw what parents would pack for the children to eat for their snacks and lunches and they weren't always the most healthy choices, especially for the children who were overweight. Childhood obesity is really the parent's responsibility' (b15). This also maps to the survey findings mentioned above, where 39\% placed responsibility on children for reducing childhood obesity, against the $91 \%$ who blamed parents ${ }^{(14)}$.

From an adult perspective, this creates some common ground for restricting choice in schools and child care settings, although contention seemed to begin at a 'cupcake line' about bake sales and birthdays in schools. One parent said, 'I think it's important that proper foods be available for kids. I do think we have to be careful we're not being "super food police". Never having a cupcake cross the door is, I think, a little bit extreme' (b3). Another commented 'let's not turn into food Nazis!' (b19). A third complained, 'telling people that they can't sell cookies for a fundraiser, I mean gimme a break' (b20).

\section{Implications}

The current study does not capture the distribution of the values discussed here, their potential association with demographic characteristics, nor necessarily all possible choice frames. However, the quality of the views and 
values about 'choice' expressed by the participants in the study at least partially reflect those in the larger US public discussion about choice and childhood obesity prevention policy. The choice-as-freedom frame appears in examples from politicians and popular media cited here. Previous research mentioned above reflects the other two frames.

The present research illustrates the complexity and non-exclusivity of these frames and the values underlying them. It particularly teases out freedom $v$. responsibility values that surveys possibly conflate and the media obesity framing research has ignored. Taking these values underlying concerns about 'choice' in the USA into account, the strategies proposed below may help smooth paths to democratic public action on obesity prevention in the USA.

\section{Use multiple frames for public bealtb policy}

Some obesity prevention policies can be framed not only in terms of public health benefits through contextual changes, but also as supports for greater choice. For example, 'freedom of choice' arguments were made against the recent toy restrictions in children's fast-food meals in Santa Clara County in California. However, such a policy could be framed as increasing freedom of choice, since customers at the most affected restaurant chain, at least, can now elect to buy the toy separately for about a dollar while the child meal packages are now about a dollar cheaper. However, this information does not appear in the mainstream media coverage of this policy, including in recent coverage of similar proposals for New York City. Similarly, if zoning laws required sidewalks in new housing developments, this would increase options for active transport. Acknowledging the role of personal and parental responsibility in the context of policy proposals is likely also wise. For example, not allowing restaurants to bundle the toys with particular meals lets parents help their children select from healthier menu options without necessarily denying them a toy.

However, each frame also carries social risks. The responsibility frame can employ socially acceptable values of individual accountability as a cover for stigmatizing fat people and possibly for race or class discrimination ${ }^{(18,19)}$. A study of causal attribution in news media found that articles that mentioned the poor, blacks, or Latinos were statistically more likely, compared to those that did not mention these groups, to ascribe higher weights to poor food or exercise choices, ${ }^{(17)}$. (This is with some irony, given inequitable environmental contexts, including disproportionate marketing of 'poor choices' in neighbourhoods of colour ${ }^{(20)}$.) In the present study, one single mother managing on little income responded to a proposal to motivate and educate parents about childhood obesity with, 'it sounded a little bit like condescending, like we're going to educate you on why you're fat' (b18). The context frame can also pose risks, as people may feel it undermines accountability values and, therefore, may backfire in the USA ${ }^{(21)}$.

\section{Make policy choices}

Citizens, including children, can bring their priorities and values to the table, consider the evidence, and negotiate and decide what to do. For example, involving schoolchildren in developing a milk policy for their school lunchroom supports autonomy more deeply than a choice between white and chocolate milk. A community obesity prevention project stakeholder told this story:

It has to be a slow process with the people you're trying to engage. They ultimately have to demand it. I was at a meeting the other day. At the end this woman [said] 'please don't have chips next time, I don't want to eat them and the fact that you have them here and I'm stuck in this room for $4 \mathrm{~h}$ '. And I was like 'beautiful, you're demanding it'. (c5)

Facilitated discussion about these issues may facilitate consensus and compromises, as in some parent focus groups on childhood obesity ${ }^{(22)}$. The interviews following statement sorts with the 'set B' group in the present study often led participants to express increasingly complex and nuanced views on obesity prevention ${ }^{(1)}$. Approaches to this might include traditional consciousness raising about constraints on agency ${ }^{(24)}$ to help reconcile differences in views on what contexts enable autonomy. Such discussion also can provide an opening to question the equation of personal autonomy with superficial choices. Public health ethicist Nys suggests that choice is about autonomy only when rooted in a person's value-system, ${ }^{(24)}$ (p. 66), not simply between white or chocolate milk.

Evidence briefs that summarize existing research, about choice generally and influences on food and activity choices particularly, can inform the public dialogues advocated above (e.g. ${ }^{(25-27)}$ ).

\section{Expand research agendas about choice}

Two arenas ripe for research include the individual and social impacts of facing choices and the amount of free will, or conscious choice, we are able to exercise. In psychology, a growing body of research demonstrates negative personal and social impacts of emphasizing freedom of choice and of facing extensive menu-like choices. These impacts include reductions in ability to make subsequent conscious choices and in empathy for others $^{(28-31)}$. In nutrition, two popular books summarize research on the biological and micro-psychological impacts on our food choices ${ }^{(33,34)}$ and open for question how much autonomy humans actually are able to exercise in both the quality and quantity of food they eat. However, large gaps remain in understanding how macroenvironments impact obesity-related behaviour ${ }^{(34)}$. 
One immigrant in the present study mocked the limited choices on many American menus, 'I eat pizza or I eat hamburgers and fries. No I eat hot dogs. There's some kids who only ever eat pizza and that's their personal choice but it obviously is within the choices offered' (b7). Perhaps we need choices on a larger scale. The Ottawa Charter for Health Promotion defines that field's work as 'enabling people to increase control over, and to improve, their health'(35). Such control implies a deep autonomy; not a choice between crispy or grilled chicken, but between developing main streets packed with fast-food chains or building communities that offer a full range of restaurants and grocery stores, and perhaps a recreation centre and park too.

\section{Acknowledgements}

Funding for travel, software and transcripts was provided by Hatch and Smith-Lever grants and a Cornell Human Ecology Alumnae Association student grant. There are no conflicts of interest to report. The author designed the study, conducted about a third of the interviews, and completed all of the analysis, interpretation and manuscript production for the present paper. The author is grateful to the interview teams, to David Pelletier and Jemila Sequeira for their guidance during data collection, and especially to all of the research participants for sharing their perspectives and insights. Thanks also go to David Pelletier, Kathleen Rasmussen, Sofia Villenas and Scott Peters for their review of the dissertation chapter that led to this paper.

\section{References}

1. Porter CM \& Pelletier DL (2011) Finding common ground: perspectives on community-based childhood obesity prevention. Health Promot Pract (Epublication ahead of print version).

2. Bateson G (1955/1987) Steps to An Ecology of Mind: Collected Essays in Anthropology, Psychiatry, Evolution, and Epistemology. Northvale, NJ: Aronson.

3. Goffman E (1974/1986) Frame Analysis: An Essay on the Organization of Experience. York, PA: Maple Press.

4. Dorfman L \& Wallack L (2007) Moving nutrition upstream: the case for reframing obesity. J Nutr Educ Behav 39, 2 Suppl., S45-S50.

5. Fairclough N (2003) Analysing Discourse: Textual Analysis for Social Research. London/New York: Routledge.

6. Porter C (2007) Ottawa to Bangkok: changing health promotion discourse. Health Promot Int 22, 72-79.

7. Minkler M (1999) Personal responsibility for health? A review of the arguments and the evidence at century's end. Health Educ Behav 26, 121-141.

8. Harsanyi D (2007) Nanny State: How Food Fascists, Teetotaling Do-Gooders, Priggish Moralists, and Other Boneheaded Bureaucrats are Turning America into a Nation of Children. New York: Broadway Books.

9. Martinez M (2010) Mayor vetoes San Francisco ban on Happy Meals with toys. http://articles.cnn.com/2010-11-12/ us/california.fast.food.ban_1_childhood-obesity-shape-upsan-francisco-food-desert?_s=PM:US (accessed February 2012).
10. Office of Cable Television (2011) Council of the District of Columbia Committee of the Whole Public Roundtable. http:// oct.dc.gov/services/on_demand_video/channel13/June2011/ 06_16_11_COW_2.asx (accessed June 2011).

11. Lupton D (1995) The Imperative of Health. London: Sage.

12. Steim RI \& Nemeroff CJ (1995) Moral overtones of food: judgments of others based on what they eat. Pers Soc Psychol Bull 21, 480-490.

13. Puhl RM \& Brownell KD (2006) Confronting and coping with weight stigma: an investigation of overweight and obese adults. Obesity (Silver Spring) 14, 1802-1815.

14. Evans WD, Finkelstein EA, Kamerow DB et al. (2005) Public perceptions of childhood obesity. Am J Prev Med 28, 26-32.

15. Lawrence RG (2004) Framing obesity: the evolution of news discourse on a public health issue. Harvard Int $J$ Press/Politics 9, 56-75.

16. Kim S-H \& Willis LA (2007) Talking about obesity: news framing of who is responsible for causing and fixing the problem. J Health Commun 12, 359-376.

17. Saguy AC \& Almeling R (2008) Fat in the fire? Science, the news media, and the 'obesity epidemic'. Sociol Forum $\mathbf{2 3}$, 53-83.

18. Evans JB \& LeBesco K (editors) (2001) Bodies Out of Bounds: Fatness and Transgression. Berkeley, CA: University of California Press.

19. Kumanyika S (2005) Obesity, health disparities, and prevention paradigms: hard questions and hard choices. Prev Chronic Dis 2, issue 4, A02.

20. Grier SA \& Kumanyika SK (2008) The context for choice: health implications of targeted food and beverage marketing to African Americans. Am J Public Health 98, 1616-1629.

21. Gollust SE, Lantz PM \& Ubel PA (2009) The polarizing effect of news media messages about the social determinants of health. Am J Public Health 99, 2160-2167.

22. Lewin AC (2009) Whose responsibility? The role of the federal government in preventing childhood obesity: perspectives of organizations, congressional staffers, and parents. PhD Dissertation, Cornell University.

23. Travers KD (1997) Nutrition education for social change: critical perspective. J Nutr Educ 29, 57-62.

24. Nys TRV (2008) Paternalism in public health care. Public Health Ethics 1, 64-72.

25. Healthy Eating Research (2007). School Foods Sold Outside of Meals (Competitive Foods). http://www.healthyeating research.org/images/stories/her_research_briefs/hercompet foodsresearchbrief.pdf (accessed February 2012).

26. Robert Wood Johnson Foundation (2008) Food and Beverage Marketing to Children and Adolescents: What Changes are Needed to Promote Healthy Eating Habits? Princeton, NJ: Robert Wood Johnson Foundation.

27. Active Living Research (2009) Walking and Biking to School, Physical Activity and Health Outcomes. http://www. activelivingresearch.org/files/ALR_Brief_ActiveTransport.pdf (accessed February 2012).

28. Vohs KD, Baumeister RF, Schmeichel BJ et al. (2008) Making choices impairs subsequent self-control: a limitedresource account of decision making, self-regulation, and active initiative. J Pers Soc Psychol 94, 883-898.

29. Baumeister RF, Sparks EA, Stillman TF et al. (2008) Free will in consumer behavior: self-control, ego depletion, and choice. J Consum Psychol 18, 4-13.

30. Botti S \& Hsee CK (2010) Dazed and confused by choice: how the temporal costs of choice freedom lead to undesirable outcomes. Organ Behav Hum Decis Process 112, 161-171.

31. Savani K, Stephens NM \& Markus HR (2011) The unanticipated interpersonal and societal consequences of choice. Psychol Sci 22, 795-802. 
32. Wansink B (2006) Mindless Eating: Why We Eat More Than We Think. New York: Bantam Books.

33. Kessler DA (2009) The End of Overeating: Taking Control of the Insatiable American Appetite. New York: Rodale Inc.
34. Kirk SFL, Penney TL \& McHugh TLF (2009) Characterizing the obesogenic environment: the state of the evidence with directions for future research. Obes Rev 11, 109-117.

35. Ottawa Charter (1986) Ottawa Charter for health promotion. Health Promot Int 1, iii-v. 